Abstract FRI0349 - Table 1. Organ involvements in patients

\begin{tabular}{|c|c|c|c|c|c|c|c|}
\hline \multirow[t]{2}{*}{ Organ involvements } & \multirow[t]{2}{*}{ AA } & \multirow[t]{2}{*}{$A C$} & \multirow[t]{2}{*}{$\mathrm{CC}$} & \multirow[t]{2}{*}{$\mathrm{p}$-value } & \multicolumn{3}{|c|}{$\mathrm{p}$-values of multiple comparisons ${ }^{\dagger}$} \\
\hline & & & & & $A A$ vs. $A C$ & AA vs. CC & AC vs. $C C$ \\
\hline Carotid arterial lesion & $78.9 \%(15 / 19)$ & $63.9 \%(23 / 36)$ & $80.0 \%(8 / 10)$ & $0.48^{\star}$ & 1.00 & 1.00 & 1.00 \\
\hline Descending aortic lesion & $75.0 \%(18 / 24)$ & $44.2 \%(19 / 43)$ & $25.0 \%(4 / 16)$ & $0.0048^{\star}$ & 0.064 & 0.0096 & 0.71 \\
\hline eGFR (ml/min/1.73m²) & $61.3 \pm 26.9$ & $72.9 \pm 22.8$ & $81.5 \pm 28.8$ & $0.011^{\star \star}$ & 0.21 & 0.042 & 0.75 \\
\hline
\end{tabular}

Mean $\pm \mathrm{SD}$, *Fisher's exact test, ${ }^{* *}$ one-way ANOVA, ${ }^{\dagger} \mathrm{p}$-value is corrected by Bonferroni's method.

them into three groups according to the allele at the SNP, AA $(n=26), A C(n=43)$ and $C C(n=16)$ (A is a risk allele), and investigated the association of the SNP and organ involvements.

Results: There were no differences in the complication rates of carotid arterial lesions among the groups (AA 78.9\%, AC 63.9\% and CC $80.0 \%$ ). The proportion of patients with lesions in descending aorta (Numano classification ${ }^{2}$ llb $\sim \mathrm{V}$ ) was $75.0 \%$ in $\mathrm{AA}, 44.2 \%$ in $\mathrm{AC} 44.2 \%$ and $25.0 \%$ in $\mathrm{CC}$ and the proportion in $A A$ was significantly higher than in $C C(p=0.0096)$. Moreover, estimated glomerular filtration rate (eGFR) was significantly lower in AA than in CC $\left(61.3 \pm 26.9 \mathrm{ml} / \mathrm{min} / 1.73 \mathrm{~m}^{2}\right.$ vs. $\left.81.5 \pm 28.8 \mathrm{ml} / \mathrm{min} / 1.73 \mathrm{~m}^{2}, \mathrm{p}=0.042\right)$.

Conclusions: The SNP rs6871626 located in $I L 12 B$ may influence on the occurrence of descending aortic lesions in TAK patients and this may lead to renal dysfunction.

References:

[1] Terao C et al. Am J Hum Genet. 2013; 93(2): 289-97.

[2] Hata A et al. Int J Cardiol. 1996; 54 Suppl: S155-163.

Disclosure of Interest: None declared

DOI: 10.1136/annrheumdis-2017-eular.4548

\section{FRI0350 INVESTIGATING THE LINK BETWEEN ISCHEMIC HEART DISEASE AND BEHCET'S DISEASE: A CROSS-SECTIONAL ANALYSIS}

Y. Yavne ${ }^{1}$, S. Tiosano ${ }^{2}$, A. Watad ${ }^{2}$, D. Comaneshter ${ }^{3}$, A.D. Cohen ${ }^{3,4}$

H. Amital ${ }^{2} .{ }^{1}$ Sackler Faculty of Medicine, Tel Aviv University, Tel Aviv;

2Department of Medicine 'B', Zabludowicz Center for Autoimmune Diseases,

Sheba Medical Center, Tel Hashomer: ${ }^{3}$ Chief Physician's Office, Clalit Health

Services, Tel Aviv; ${ }^{4}$ Siaal Research Center for Family Medicine and Primary

Care, Faculty of Health Sciences, Ben Gurion University of the Negev, Beer

Sheva, Israel

Background: Behcet's disease (BD) is a multi-systemic chronic inflammatory disorder which involves the vasculature tree of all sizes. Subclinical endothelial injury as a result of chronic inflammation in BD has been associated with thrombosis and arterial stiffness, risk factors for ischemic heart disease (IHD) ${ }^{1-4}$. However, data regarding the association between $\mathrm{BD}$ and IHD and the impact of various risk factors on this association, is scarce ${ }^{3-5}$

Objectives: To examine the association between $\mathrm{BD}$ and the development of IHD and its potential impact as a cardiovascular risk factor.

Methods: This study was conducted as a case-control study utilizing the database of Clalit Health Services. The proportion of IHD was compared between patients diagnosed with $\mathrm{BD}$ and age- and gender-matched controls. Univariate analysis was performed using Chi-square and student $t$-test and a multivariate analysis was performed using a logistic regression model.

Results: $871 \mathrm{BD}$ patients and 4,439 age- and gender-matched controls were included in this study. The proportion of IHD amongst BD patients was increased in comparison with controls $(10.9 \%$ vs. $7.52 \%$ respectively, $p$-value $=0.001)$. After controlling for cofounders, BD was associated with IHD on multivariate analysis (odds ratio $1.485,95 \%$ confidence interval 1.106-1.982, Table 1). When the comparison between BD patients with IHD and controls with IHD was stratified according to risk factors, age younger than 70 and male gender were both found to be significantly elevated in the BD group.

Table 1. Multivariate logistic regression for IHD $(n=5,220)$

\begin{tabular}{lccc}
\hline Variable & OR & $95 \% \mathrm{Cl}$ & $p$-value \\
\hline Behcet & 1.485 & $1.106-1.982$ & 0.008 \\
Age & 1.059 & $1.047-1.071$ & $<0.001$ \\
Male gender & 2.929 & $2.248-3.841$ & $<0.001$ \\
BMl & 1.010 & $0.987-1.034$ & 0.388 \\
High SES vs. Iow & 0.709 & $0.503-0.994$ & 0.048 \\
Intermediate SES vs. low & 0.793 & $0.600-1.048$ & 0.104 \\
Arab ethnicity & 0.872 & $0.618-1.221$ & 0.430 \\
Hypertension & 3.050 & $2.332-4.010$ & $<0.001$ \\
Hyperlipidemia & 7.895 & $5.119-12.781$ & $<0.001$ \\
Diabetes & 1.624 & $1.268-2.078$ & $<0.001$ \\
Smoking & 1.849 & $1.445-2.371$ & $<0.001$
\end{tabular}

$\mathrm{IHD}=$ ischemic heart disease, $\mathrm{OR}=$ odds ratio, $\mathrm{Cl}$ = confidence interval, $\mathrm{BMI}=$ body mass index, $\mathrm{SES}=$ socioeconomic status.

Conclusions: BD patients have an increased proportion of IHD in comparison with matched controls. The population of BD patients with IHD has a higher proportion of younger males in comparison with controls with IHD. Preemptive screening for IHD may be warranted in this subgroup.

References:

[1] Uyar B, Solak A, Genç B, et al. Evaluation of Arterial Stiffness in Patients with Behcet's Disease by Using Noninvasive Radiological Methods such as Intima-Media Thickness of the Carotid, Ankle-Brachial Pressure Index, Coronary Artery Calcium Scoring, and Their Relation to Serum Fetuin-A Levels: A Case-Control Study. Ann Dermatol. 2015;27:702.

[2] Springer J, Villa-Forte A. Thrombosis in vasculitis: Curr Opin Rheumatol. 2013;25:19-25.

[3] Misra DP, Shenoy SN. Cardiac involvement in primary systemic vasculitis and potential drug therapies to reduce cardiovascular risk. Rheumatol Int. 2016;37.1:151-167.

[4] Pandey A, Garg J, Krishnamoorthy P, et al. Predictors of Coronary Artery Disease in Patients with Behcet's Disease. Cardiology. 2014;129:203-206.

[5] Seyahi E, Memisoglu E, Hamuryudan V, et al. Coronary atherosclerosis in Behçet's syndrome: a pilot study using electron-beam computed tomography. Rheumatology. 2004;43:1448-50.

Disclosure of Interest: None declared

DOI: 10.1136/annrheumdis-2017-eular.2936

\section{FRI0351 PAPULOPUSTULAR LESIONS ACCORDING TO AGE, SEX AND LOCALIZATION IN BEHCET'S SYNDROME PATIENTS COMPARED HEALTHY AND DISEASED CONTROLS}

Z. Kutlubay ${ }^{1}$, Y. Ozguler ${ }^{2}$, G. Hatemi ${ }^{2}$, K. Tascilar $^{3}$, C. Mat ${ }^{1}$, H. Yazici ${ }^{2}$. ${ }^{1}$ Department of Dermatology; ${ }^{2}$ Department of Internal Medicine Division of Rheumatology, Istanbul University Cerrahpasa Medical Faculty; ${ }^{3}$ Department of Internal Medicine, Okmeydani Research and Training Hospital, Istanbul, Turkey

Background: Papulopustular lesions (PPL) are the most common skin lesions in Behçet's syndrome (BS).

Objectives: To assess whether PPL are different in BS according to localization, age, sex and medications used when compared to rheumatoid arthritis patients (RA) and apparently healthy subjects (HS).

Methods: 209 consecutive BS patients who were routinely followed in our dedicated BS center were studied. Patients with RA $(n=146)$ who were followed up in the rheumatology outpatient clinic of the same unit and HS $(n=149)$ were used as controls. All subjects were clinically evaluated by the same dermatologist and all skin lesions (papules, pustules, comedones, folliculitis, cysts, nodules) on the face, trunk and legs were separately counted. Information regarding the demographic and clinical features of primary disease and medications used were obtained from patients' charts.

Results: Subjects without PPL were excluded before analyses. Demographic features and mean number of PPL according to site of body were summarized in Table-1. Mean number of total PPL were similar between BS and HS and significantly higher than in RA $(p<0.001)$. Mean number of total PPL according to sex were similar in RA and HS but higher in male BS patients compared to female BS patients $(p=0.04)$. When we analyzed the number of PPL according to different body sites, we observed that BS patients had significantly more lesions on the legs when compared to the RA patients and HS $(p<0.0001)$. Number of PPL lesions tend to decrease as the patient ages in BS similar to RA and HS. When leg lesions were analyzed according to age, this difference remained in the age groups $31-50$ and $>50$ but not in the age group $\leq 30$. Corticosteroid use did not impact the results.

Table 1

\begin{tabular}{lccc}
\hline \multicolumn{1}{c}{ BS } & RA & HS \\
\hline $\mathrm{N}$ & $155(74 \%)$ & $57(39 \%)^{\star}$ & $101(68 \%)$ \\
$\mathrm{F} / \mathrm{M}$ & $95 / 60$ & $46 / 11$ & $52 / 49$ \\
Mean age (SD) & $38.6(10.0)$ & $47.5(13)^{\dagger}$ & $34.7(12.0)$ \\
$\mathrm{N}$ of pts on corticosteroids & $24(15 \mathrm{M} / 9 \mathrm{~F})(15 \%)$ & $37(9 \mathrm{M} / 28 \mathrm{~F})(65 \%)$ & - \\
Mean n of PPL (SD) & $7.8(8.0)$ & $3.9(3.8)^{\ddagger}$ & $9.7(9.5)$ \\
Trunk & $107(58 \mathrm{~F} / 49 \mathrm{M})(70 \%)$ & $36(28 \mathrm{~F} / 8 \mathrm{M})(63 \%)$ & $81(37 \mathrm{~F} / 44 \mathrm{M})(80 \%)$ \\
Face & $120(80 \mathrm{~F} / 40 \mathrm{M})(77 \%)$ & $37(32 \mathrm{~F} / 5 \mathrm{M})(65 \%)$ & $84(50 \mathrm{~F} / 34 \mathrm{M})(83 \%)$ \\
Legs & $48(21 \mathrm{~F} / 27 \mathrm{M})^{\S}(31 \%)$ & $2(1 \mathrm{~F} / 1 \mathrm{M})(3.5 \%)$ & $13(5 \mathrm{~F} / 8 \mathrm{M})(13 \%)$ \\
\hline
\end{tabular}

${ }^{*} p<0.001,{ }^{\dagger} p<0.02,{ }^{\ddagger} p<0.05,{ }^{\S} p<0.0001$

Conclusions: BS patients have significantly more PPL on the legs when compared to HS and RA. Number of PPL tend to decrease as the patient ages in BS similar to RA and HS however BS patients still have more PPL on the legs after the age of 50 suggesting that these lesions somehow differ from acne vulgaris, in pathogenesis

Disclosure of Interest: None declared

DOI: 10.1136/annrheumdis-2017-eular.6463 